\title{
Hospital das Clínicas of University of São Paulo Medical School
}

\section{Carlos Roberto Ribeiro Carvalho ${ }^{1}$, Eloisa Silva Dutra de Oliveira Bonfá ${ }^{2}$, Antonio José Rodrigues ${ }^{3}$}

y the end of the nineteenth century, there were
only two medical schools in Brazil, with one in Bahia and one in Rio de Janeiro. Despite several attempts to establish a medical school in São Paulo, there was not enough support from the imperial government for its implementation. Thus, it was only after the proclamation of the Republic that a law establishing a medical school in São Paulo was sanctioned, in November 1891, by the State President Américo Brasiliense. However, it was only 21 years later, on December 19, 1912, during Rodrigues Alves' third term as President of the State, that the law that implemented the São Paulo School of Medicine and Surgery was bestowed. Arnaldo Vieira de Carvalho, who was the Clinical Director of Santa Casa da Misericórdia, was appointed to be in charge of the implementation of the first medical course in the State of São Paulo. The first class was taught on April 2, 1913, and the first group of students, consisting of 27 doctors, including two women, graduated in 1918.

The building of the School of Medicine, constructed mostly with funds from the Rockefeller Foundation, was inaugurated in 1931. Its integration with the Universidade de São Paulo occurred from January 1934 on, when it started being called Universidade de São Paulo School of
Medicine. Practical clinical and surgery classes continued to be taught at Santa Casa de Misericórdia of São Paulo until April 1944, when Hospital das Clínicas (Clinical Hospital) of the USP School of Medicine was founded. From the beginning of discussions in 1915, both São Paulo physicians and the representatives of the Rockefeller Foundation intended to create a public health school in South America, focusing on a better medical education, based on a smaller number of vacancies, emphasizing research and relying on full-time professors, and to establish the university's own hospital.

The building of Hospital das Clínicas (Clinical Hospital) began in October 1938, under Doctor Adhemar de Barros' government. When the hospital was completed, Professor Benedito Montenegro was the Dean of the Faculty of Medicine and President of the Board of Directors. Hospital das Clínicas was founded by federal intervenor Fernando Corrêa da Costa on then-President Getúlio Vargas' birthday. Our hospital had already been "born" as a reference hospital and was recognized as the largest in Latin America. At the time, its capacity was 423 beds.

By statute, the purpose of the hospital was to provide medical-hospital assistance; to serve as a site for

1. Vice-Clinical Director of the Hospital das Clínicas of University of São Paulo Medical School (Hospital das Clínicas da Faculdade de Medicina da Universidade de São Paulo - HCFMUSP); MD and Full Professor.

2. Clinical Director of the Hospital das Clínicas of University of São Paulo Medical School (Hospital das Clínicas da Faculdade de Medicina da Universidade de São Paulo-HCFMUSP); MD and Full Professor.

3. Superintendent of the Hospital das Clínicas of University of São Paulo Medical School (Hospital das Clínicas da Faculdade de Medicina da Universidade de São Paulo - HCFMUSP); Engineer.

Mailing address: Superintendence of the HCFMUSP. Av. Dr. Ovídio Pires de Campos, 225. Administration Building - Ground Floor. Cerqueira César - São Paulo - SP. ZIP CODE: 05403-010 
the education of medical students, doctors and nurses; to provide means for the development of scientific research; and to contribute to the population's health education. The hospital specifically comprised a Board of Directors, a Medical Division, a Technical Services Division and an Administrative Division. The Medical Division was headed by the clinical staff, and its goal was to perform the medical activities of examination, diagnosis, patient treatment, education, investigation and research. In the Medical Division, there was a Surgery Subdivision, a Medicine Subdivision and an Auxiliary Subdivision. Beginning in the second half of the last century, the Medicine Subdivision comprised the First Medical Clinic, the Second Medical Clinic, Clinical Therapeutics, the Tropical and Infective Diseases Clinic, the Dermatologic and Syphiligraphic Clinic, the Neurological Clinic, the Pediatric and Child Care Clinic and the Psychiatric Clinic.

From 1954 on, clinical specialties began to take form and become organized. For example, the Second Medical Clinic was ultimately composed of the following areas: Cardiology, Gastroenterology, Rheumatology, Propaedeutic and Pulmonology.

From the 1950s on, the hospital experienced constant growth. The original building became the Central Institute (CI), and the hospital became a hospital complex, currently consisting of eight Institutes and two Auxiliary Hospitals: Cotoxó, in the Pompéia neighborhood in the western zone of the capital of São Paulo, and Suzano, in the metropolitan area of the Greater São Paulo area. Patients who need a longer period of hospitalization are transferred to these locations. The complex occupies an area of 352000 $\mathrm{m}^{2}$ and provides 2470 beds to its patients.

The Central Institute of the Clinical Hospital (Instituto Central do Hospital das Clínicas - ICHC) is home to most of the medical and surgical clinical specialties and is where a Referenced Emergency Unit, our Central Emergency Hospital, is located; this unit provides services in cases of high complexity. It is worth mentioning the work of the multi-professional teams, including the Nutrition and Dietetics Division, which was the first nutrition unit in a public hospital in Brazil and in the Mercosur to earn the NBR ISO 9001 certification. The unit also houses the Ambulatory Building (Prédio dos Ambulatórios - PAMB), founded in 1981, which offers treatment to outpatients, and features areas for diagnostic and therapeutic support. The structure additionally includes the Pharmacy Division, which is responsible for a system of individualized dosing of drugs to serve the beds at the institute. Moreover, this building hosts the largest surgical center in the complex and the Central Laboratory Division, which was the first area in Hospital das Clinicas and the first public service laboratory in the country to receive the ISO 9002 certificate. This division also now has accreditations from the Brazilian Society of Clinical Pathology/Laboratory Medicine, the College of American Pathologists, and the National Accreditation Organization and the NBR ISO 9001:2008 and 14001:2004 and OHSAS 18001:2007 certifications.

ICHC, which features more than $165000 \mathrm{~m}^{2}$ of floor space, provides 914 beds and 31 surgery rooms. Annually, more than 35000 patients are admitted, approximately 110000 cases requiring urgent and emergency care are managed, more than 26000 surgeries are performed, and more than 720000 cases are provided ambulatory care services.

In the $1940 \mathrm{~s}$, patients injured in traffic and construction accidents occupied many of Hospital das Clínicas' beds; this was a time at which São Paulo was growing at a fast pace. At the time, the city was also experiencing a polio epidemic. The creation of a place to address cases of trauma and infantile palsy was urgently needed. The President at that time, Getúlio Vargas, who had lost a child to poliomyelitis, authorized the building of Brazil's largest hospital specializing in orthopedics.

Thus, in 1953, the Orthopedic and Trauma Clinic was inaugurated. It was the first specialized clinic to leave the Hospital das Clínicas' building, where it occupied two floors. With the eradication of poliomyelitis, the hospital began to be used for medical care, research and teaching of other major orthopedic afflictions. Currently, the "F. E. Godoy Moreira" Institute of Orthopedics and Traumatology (Instituto de Ortopedia e Traumatologia - IOT) occupies $25000 \mathrm{~m}^{2}$ of built area, with 9 surgery rooms, 32 medical clinics, 144 beds, seven specialty laboratories and 1100 employees. Annually, the institution holds over 95000 ambulatory consultations and performs approximately 6100 surgeries, more than 25000 people are treated 
in its Emergency Room, and more than 5700 patients are admitted. Its medical staff includes more than 170 physicians dedicated to the treatment of diseases of the locomotor system. IOT is recognized as one of the leading research centers in Brazil, and it was the FIFA Center of Excellence during the World Cup in 2014. It is also the only center with a team specialized in 24-hour replantation of extremities, and it is among the most important orthopedics and traumatology hospitals in Latin America.

The Psychiatric Clinic was installed in Hospital das Clinicas in January 1945, with the goal of providing the best medical care to patients in this specialty. The building for the Institute of Psychiatry (Instituto de Psiquiatria - IPq) was inaugurated in April 1952 with the beginning of ambulatory services. By coincidence, the first neuroleptic/antipsychotic drug started being used that same year. In October 1953, the infirmary started to operate. Currently, the IPq performs more than 96000 ambulatory consultations and 2300 hospitalizations per year, and it is now considered to be the most important and best-equipped psychiatric center in Brazil. Its team includes specialists in multiple areas of medicine, technical support staff and a full administrative sector. The infrastructure comprises general and specialized ambulatory services, laboratories and diagnostic services, a day hospital, inpatient units, rehabilitation centers, psychotherapy, dental care for psychiatric patients and a functional neurosurgery division that is a national reference center. The institute has 110 beds and four surgery rooms, and it performs more than 1300 surgeries per year.

The Children's Institute (Instituto da Criança ICr) was created through State Decree No. 52481 on July 2, 1970, with the aim of being the teaching hospital for subjects taught by the Department of Pediatrics and Child Care Department of the USP Faculty of Medicine. Founded in 1976, ICr ceased to be a CI ward and became one of the HCFMUSP units. There, clinical and surgical care is provided to patients in the first two decades of life. The facilities include, in addition to the original $\mathrm{ICr}$ building, the Child Cancer Treatment Institute (Instituto do Tratamento do Câncer Infantil - Itaci) and the Nursery Annexed to the Maternity (Berçário Anexo à Maternidade - BAM), located on the 10th floor of ICHC. The hospital specializes in treating children and teenagers with serious, complex and rare diseases and was recognized by the Ministry of Health in 1999 as a National Reference Center for Children's Health. Its 24-specialty ambulatory services assist an average of 7000 children and adolescents per month. With 226 beds and four surgery rooms, the hospital performs 2100 surgeries annually and more than 7600 hospitalizations and provides approximately 27000 cases with urgent and emergency care. The medical staff is composed of more than 330 specialists. $\mathrm{ICr}$ has been involved in several important events in the history of health in the country, such as the first liver transplant, performed in 1989 .

The Decree-Law No. 42.817 of 1963 created the Institute of Cardiopulmonary Diseases. However, the performance of the first heart transplant in May 1968, six months after the groundbreaking transplant in South Africa, allowed for political initiatives and resources supporting the building of the Heart Institute (Instituto do Coração InCor), initiated in 1969. Inaugurated in January 1977, this institute is one of three major heart centers in the world in terms of both the volume of services and the number of cardiology and pulmonology subspecialties gathered in a single hospital. Thus, since 2006, the institute has encompassed virtually all activities related to cardiology and respiratory medicine, both in the clinical and in the surgical areas, including pediatric cases in the field of cardiology. In addition to being a service center for the population, from prevention to treatment, InCor stands out as a major research and teaching center. Approximately 3000 employees work on its premises; $40 \%$ of these professionals have pursued higher education, and $10 \%$ of them have completed post-graduate studies at Brazilian and/or foreign institutions.

InCor comprises two buildings occupying 75000 $\mathrm{m}^{2}$ of built area, and the construction of a third block is currently in progress. The hospital offers its patients 449 beds arranged in seven wards, among which 158 beds are in the ICU, 14 are in surgery rooms, and 7 are in hemodynamics and electrophysiological study rooms, in addition to a dedicated area for clinical research. Annually, InCor provides an average of 200000 medical consultations, 37000 multi-professional services, 13000 hospitalizations, 6000 surgeries, 3 million clinical analyses, 350000 high complexity diagnostic tests and approximately 25000 urgent and emergency services. 
The Radiology Institute of Hospital das Clínicas (Instituto de Radiologia - InRad) was founded on November 4, 1994, with the mission of promoting scientific knowledge through teaching, research, training and capacity building of human resources, and provision of health care services and treatment in the fields of diagnostic imaging and therapeutic oncology.

With a built area of $18000 \mathrm{~m}^{2}$, InRad runs over 300000 tests per year. The complex offers its patients over 70 cutting-edge technological devices for performing tests and high-complexity procedures for an extensive range of diseases. The site also features teams specialized in Clinical Engineering, Civil Engineering, Maintenance and Architecture, which actively participate in the process of constant renewal and modernization of the equipment and facilities to ensure a high level of image quality and, consequently, greater diagnostic accuracy. InRad provides the complex with a storage system and a system for digital distribution of images, or the Radiology Information System (RIS)/Picture Archiving and Communication System (PACS), which grants access to information from any of the units in the hospital and eliminates the need for printing reports and test images.

The structure of InRad consists of two major divisions: 1) General Radiology: Conventional and Contrast Radiology; Breast Imaging; Interventional Radiology (Neuroradiology and Cascular); MRI; Computed Tomography; Ultrasonography and Emergency Radiology. 2) Oncology: Radiotherapy-Radiosurgery and Nuclear Medicine; Cyclotron Unit for the Production of Radiopharmaceuticals.

Inaugurated in May 2008, the Octavio Frias de Oliveira Cancer Institute of the State of São Paulo (Instituto do Câncer do Estado de São Paulo - ICESP) was created as a Social Health Organization by the State Government in partnership with the Faculty of Medicine Foundation, with the aim of establishing the largest hospital specialized in cancer treatment in Latin America. It currently integrates the Special Autarchy as one of the HCFMUSP institutes.

The institute's building has 28 floors and is 112 $\mathrm{m}$ high, with a built area of $83000 \mathrm{~m}^{2}$. It offers 460 beds, among which 70 are in intensive care and 15 are in surgery rooms. Approximately 6000 patients diagnosed with cancer are treated monthly, among which 800 to 900 are new cases. The patients receiving treatment at the institution find all the structure necessary for their recovery through multiprofessional and humanized care. An essential feature of the institute is the innovation in the service delivered, which allows the patient to have all stages of his/her care, from the start of his/her treatment to rehabilitation, integrated in the same place.

In 1975, the Vergueiro Professional Rehabilitation Division (Divisão de Reabilitação Profissional Vergueiro) was designed to treat people with disabilities. In 1994, it became the Rehabilitation Medicine Division of Hospital das Clínicas, and in 2009, the Institute of Physical Medicine and Rehabilitation (Instituto de Medicina Física e Reabilitação - IMRea) was created. Its goal is to serve people with temporary or permanent physical disability who are in need of rehabilitation care to develop their physical, psychological, social and professional potential. IMRea currently has five treatment units and coordinates the Lucy Montoro Rehabilitation Network Management Committee (Comitê Gestor da Rede de Reabilitação Lucy Montoro), which features eleven operational units distributed throughout cities in the interior of São Paulo and a Mobile Unit.

The differentiating features of the Hospital das Clinicas complex, which is the largest public hospital in Latin America, are not only its large numbers, including 1.5 million ambulatory consultations, 50100 surgeries, 870 imaging tests and 12.6 million laboratory tests in 2015, but also its connection to the Faculty of Medicine. This keeps the hospital at the forefront in teaching, service, research and technological innovation.

The Hospital das Clínicas complex still fulfills its goal of going beyond the walls of the complex to offer training of human resources in the health arena via investments in the renovation of the Continuing Education School (Escola de Educação Permanente) and in distance education.

However, our greatest reason to be proud is that we are able to return part of the large investment that has been made in our institution to society. In this regard, our main commitment is to qualify leaders at all levels at which we operate. These leaders must be highly competent, humble and compassionate. Above all, we hope that the leaders qualified in the Hospital das Clinicas complex continue to be aware that they should make a difference to improve our society. 